\title{
From the Editor:
}

Slavic Review publishes letters to the editor with educational or research merit. Where the letter concerns a publication in Slavic Review, the author of the publication will be offered an opportunity to respond. Space limitations dictate that comment regarding a book review should be limited to one paragraph; comment on an article should not exceed 750 to 1,000 words. The editor encourages writers to refrain from ad hominem discourse.

D.P.K.

To the Editor:

Until I read Traian Stoianovich's review of The Balkans: From Constantinople to Communism (Slavic Review, vol. 62, no. 1), I have never felt the need to respond to any of the numerous past reviews of my books. Stoianovich's review was an apparent attempt to discredit my so-called worldview and to question my scholarly objectivity masquerading as a book review. Beyond placing my book within a recent historiographic context and providing a brief description of its contents, Stoianovich gave the book as a whole short shrift. Most of the review focused on demonstrating that my "worldview ... gets in the way" of my history by listing selected examples from the text purporting to support such an allegation, implying that I manipulated historical facts to fit my preconceptions. I strongly contest this allegation and implication, but Slavic Review's editorial policy prohibits me from refuting Stoianovich's catalog of examples point by point. Suffice it to say that most can be answered by citing other examples (and pages) in the text, leading one to surmise that Stoianovich either misread parts of the book or intentionally misinterpreted it to fortify his "worldview" thesis. As for any "prevailing (anti-Orthodox) undertone of the book," only Stoianovich has ever deduced such an absurdity-most other reviewers and my students think that I am overly critical of the west and pro-Orthodox! By ignoring the book in its entirety, Stoianovich has rendered a disservice to both the work itself and the readers of Slavic Review. Those seriously interested in more balanced evaluations of the book should seek out reviews available in other journals.

DenNis P. Hupchick Wilkes University

Professor Stoianovich does not wish to reply. 